\title{
Russian North Caucasus in the First Third of the XXI Century
}

Mihail Dmitrievich Rozin

\author{
Vladimir Nikolaevich Ryabtsev
}

Valeriy Petrovich Svechkarev

Sergey Yakovlevich Suschiy

Zhanna Aleksandrovna Tumakova

Southern Federal University, Bolshaya Sadovaya str., 105/42, Rostov-on-Don, 344006, Russian Federation

\section{Doi:10.5901/mjss.2015.v6n3s2p149}

\section{Abstract}

The article considers the current situation in the Russian North Caucasus. It reviews the main trends and possible prospects of its political development, ethnodemographycal and socioeconomic evolution, sociocultural dynamics, and the potential for new administrative-territorial reforms. It is stated that despite many displays of social archaisms, the integrated development of the region in the post-Soviet period has not stopped. And the main factor for its further modernization success consists in the stability and internal dynamism of the Russian Federation. Conclusion about rather high probability of complex stabilization of this problem Russian region for 15-25 years' prospect has been made.

Keywords: The North Caucasus, ethnodemographic and sociocultural dynamics of the region, socioeconomic development, administrative-territorial reform, regional terrorist underground

\section{Introduction}

The North Caucasus is perhaps one of the most problem regions of contemporary Russia. The analysis of social reality reveals a large number of negative phenomena in various aspects of life. However, the substantive outline of the processes happening in this extremely complex and multiform Russian region is far from completed. Even a brief overview of social dynamics of the post-Soviet North Caucasus, presented in a large number of studies, finds its multilayer structure, a set of contradictory trends, local achievements and losses, the correlation of which varies not only from one republic to the other but also within their territories, and even in each aspect of their social life (Degoev \& Ibragimov, 2006; Denisova \& Ulanov, 2003; Dobaev, 2009; "Xenophobia in Southern Russia," 2004; Matishov et al., 2009; Matishov et al., 2011; "Ethnoetatism in Southern Russia," 2006; Khoperskaya \& Kharchenko, 2005; "The North Caucasus in the national strategy of Russia," 2008; Markedonov, 2005; Gammer, 2005; King, 2008; Tishkov, 2004; Tishkov, 1997).

It can probably be the next (within the post-Soviet period) development stage of this national region, in its own way no less complicated than any previous ones and, as always, requiring concerted efforts of the central government on the normalization and integrated development of the North Caucasus.

\section{Methods}

To research the problem complex of this region, the most efficient method appears to be the systemic analysis, comprising the elements of structural-functional, morphological, diachronic approaches to the study of social processes and phenomena. It requires a detailed fixation of cause-effect relations determining the dynamics of the main aspects of life in the North Caucasus, including the specificity of its ethnodemographic, sociopolitical, economic, and sociocultural development. 


\section{Discussion and Results}

The key role of the federal government in the operation of the main aspects of social life in the republics can hardly be underestimated. But it is only one point of the global impact of "big" Russia on the North Caucasus, although so powerful and overall to be by rights identified as a megafactor.

While the scale of this impact is constantly large, its sign (positive or negative) changes depending on systemic state of Russia: its political stability and socio-economic dynamism, the ability (or inability) to solve the basic problems of the development.

In other words, the long term stability of the situation in the North Caucasus depends on to what extent Russia is able to respond to the major challenges of the XXI century and the country's success in the contemporary world; vice versa, the situation in the region is a sort of indicator of the general state of the Russian Federation.

Moreover, most problems of the North Caucasus are of nationwide rather than regional origin. Of course, republican variations of federal shortcomings and inconsistencies are often more visible and desolated. However, the necessity for the improvement of situation in the North Caucasus, declared repeatedly by the country's political leaders over the recent years, assumes the similar correction within the whole Russia (Tkhagapsoev, 2007).

That is to say, the state of the North Caucasus is a complex projection of situation, prevailing in the whole Russia, on a specific multiethnic region. Accordingly, the possible dynamics of the region will anyway be significantly correlated with the development line of the Federation. Thus, the evaluation of the most expected variants for medium-term dynamics of the region implies at least common forecast of possible scenarios of the country's development.

The scenarios for the country's medium-term (15-20 years) development within the given range of options can be represented by five basic variants, denoted conventionally as optimistic, intensive, extensive, inertial decelerating, stagnationist (crisis). Analysis of the country's dynamics over the past few years indicates two most likeable variants: extensive and inertial scenarios for Russia's development, which, however, comprise a certain range of possible variants of the future.

Actually, this "gap" is outlined by two sub-variants of the inertial dynamics: from decelerating scenario (the country demonstrates a significant decrease in economic growth, science, technology, and innovation, seriously affecting its strategic capabilities and political position in the world) to inertial-growing, when Russia is unlikely to strengthen its position in global political and economic system, yet able to minimize the rate of descending into the global periphery. The most probable trajectory of Russia's development for the medium-term prospect is considered as moderately pessimistic. RF keeps its position in a group of 5-7 leading political centers of the world, meanwhile maintaining its place in the economy of the world community.

Many experts consider a possible dramatic drop in prices for energy resources to be the critical factor able to break the algorithm of functioning of the country, to bring down the federal budget and the social sphere. However, the probability of a considerable reduction in prices in source sector is very low; additionally, Russia will be able to adapt to a slight reduction without significant losses for the society. One should take into account that the development of the other world community leaders is also rich in bottlenecks, more or less seriously weakening their system positions. The European Union, the USA, Japan, even China have their own chink in their armor, at certain conditions fraught with a deep crisis and the growth of social chaos.

It should be repeated that at present Russia has a sufficient safety factor to ensure the sustainable development of the country for the nearest and medium-term prospect. In turn, it determines the corresponding futurological predictability of the North Caucasus for which the system situation of the Russian Federation remains a megafactor, prevailing over the range of all other factors.

First, one shouldt admit that, despite the correlation between the systemic dynamism and problems in the Russian North Caucasus, a series of Russian scenarios cannot be projected directly to the regional level. Options for the development of the North Caucasus are not tightly connected with the trajectory of the Russian Federation in the world economy and geopolitics. Even the most dynamic (from possible) scenario for Russia cannot turn, on a regional level, into an overall modernization of the North Caucasus, the solution for its main problems within the next 15-20 years.

This region has its own, slower algorithm of development. And the slowdown of many modernization processes in the post-Soviet North Caucasus is not always the evidence of incorrigible conservatism and autarchy of the region. The matter is, local and national communities often choose a more sustainable pace of development. The North Caucasus is not very sensitive to the higher/lower systemic dynamism of the Russian Federation, yet Russia's systemic stability is a critical factor. Again, a serious destabilization of Russia is the main condition for the collapse of the region to the social chaos and archaic character, predictable explosive growth of ethnopolitical stresses and increase in the vast range of latent conflict spheres. 
And the depth and consistency of the Russian crisis will directly determine the volume of social turbulence of its national region. However, as it has been said, there are no serious reasons for Russia's slide into a new systemic crisis. For the medium-term forecast (15-20 years), it is reasonable to proceed from the preservation of Russian political and socioeconomic stability, appropriately limiting the range of real scenarios of the North Caucasus, which should be considered by the separate spheres of social activity of the region.

\section{Political Prospect}

It is obvious that in the medium-term Russian reality no withdrawal of the region or any of its parts from the Russian Federation is expected. Under the conditions of sufficient political and socioeconomic stability, the appearance of a separatist regime, similar to Ichkeria in the 1990s, in the North Caucasus is virtually ruled out.

At present, republican power elite is totally pro-Russian and is sure to retain this quality in the foreseeable future. However, absolute political loyalty of republican governing bodies to Moscow does not exclude more or less significant elements of managerial autonomy in the region, impossible, for example, in "Russian" Russia. These elements of administrative "sovereignty" are particularly evident in socio-legal, economic, sociocultural life activity of Chechnya, Dagestan, and Ingushetia.

It is also clear that this specificity (in social and legal aspects related to the execution of Russian laws as well) will not change in the nearest future, provided that formal Russian status of these republics is retained.

\section{Administrative-Territorial Division of the North Caucasus - Resources for Transformation}

To imagine the possibility of any administrative reformation of the region, one should be aware that "people and land", i.e., demographical situation and national administrative-territorial division, are central priorities for the communities of the North Caucasus. National autonomy is recognized as the most significant collective heritage by the overwhelming part of the population. Autonomy is a value even a small part of which cannot be waived (public conscience does not take such variants seriously).

Consequently, the ideas concerning a serious change in the status of the North Caucasian republics, developed in the Russian expert literature, seem unrealizable; they can be evaluated and analyzed only in the first approximation. As one of the options put forward, was the idea of a complete administrative unification of Russian regions, i.e., deprivation of the republics of their privileged status, their reformation to the level of "ordinary" regions of the Federation.

However, the peak of such expert proposals occurred in the mid-2000s (a period of obvious success in political and socioeconomic consolidation of the Russian Federation). Even at this time, a significant part of the expert community considered these ideas extremely dangerous, indeed provocative. The past few years have shown that the supporters of conservation of administrative status quo in the North Caucasus have a more realistic view of the situation. There is no doubt that any attempt to deprive the republics of their national status will cause extremely negative reaction from the majority of the titular communities and become a much more serious factor of destabilization in the region than the one we have now.

Current North Caucasus has not only "unshakeable" profile and interrepublican borders. The region has almost exhausted opportunities for administrative and municipal transformations within the republics. Two new national districts singled out in Karachay-Cherkessia (Abaza and Nogai) are likely to become the last territory novation of this kind within the whole region. It is clear, that all other versions of administrative reforms, declared on behalf of certain nongovernmental organizations in the 1990s, have no chance for practical realization.

\section{Ethnodemographic Realities and Prospect}

The North Caucasian republics of the post-Soviet period are characterized by several common ethnodemographic trends, the main ones being de-Russification and titulization of the population, reduction in Russian-speaking ethnic communities and the overall simplification of the national structure. However, the republics differ significantly in the pace of these processes. Maximum monoethnic state is observed in Chechnya and Ingushetia, having lost the significant part of ethnic and cultural diversity back in the 1990s. By the beginning of the XXI century, the percentage of the two titular nations there reached $90-95 \%$. Obviously, there are no real alternative to the current monoethnicity in these republics, not only for a short but also for a long (20-30 years) prospect.

Dagestan, the third republic, having experienced de-Russification, has lost a significant part of the Russian population and representatives of the Russian-speaking diasporas. The growing dominance of "native" nations becomes 
one of the factors for the slowdown of the overall modernization of the national society and its integration into sociocultural life cycles of "big" Russia.

The other three republics representing the center and west of the North Caucasus (North Ossetia - Alania, Kabardino-Balkaria, and Karachay-Cherkessia), still retain a significant percentage of Russian and Russian-speaking population, the presence of which gives the titular population a living experience of interaction with native cultural core traditions of the Russian state. However, all republics are also characterized by a steady outflow of the Russian population and the reduction of Russian diasporas, which migrate after the Russians. Moreover, these ethnodemographic trends are very stable and can be projected for at least 10-20 years. If no significant correction happens in the next decade, by the second half (maximum by the middle of the XXI century.) central and western regions of the North Caucasus will repeat the scenario of the eastern part, i.e., the titular nations and a number of native Caucasian diasporas will constitute the majority of the population of local communities.

Adygea stands apart; its spatial inclusion into the territory of Krasnodar Krai, as well as the existing demographic potential of the titular national community are the main factors supporting ethnodemographic stability.

\section{Economy and Labor-Market}

Development of contemporary economy, capable of providing financial self-sufficiency of the republics is an impossible task for the region for the medium-term prospect. By 2025-2030, the economic situation within in the republics will vary, but all of them will be characterized by a fragmented (unsystematic) structure of economic complex, enclave presence of certain modern industries, the number of which, however, will grow significantly in comparison with the present situation (respectively, their total share in the local economy will be bigger).

It is essential that almost all republics of the region demonstrate their own spheres of economic growth ("Investment Atlas of Southern Russia", 2009; Lipina, 2010).

Proceeding from the dynamics of the last decade, the most promising economic positions are observed in Dagestan and Kabardino-Balkaria. Nevertheless, other republics can strengthen their production dynamics. However, this possible acceleration can hardly break the established balance of regional industrial complexes. The main part of new manufactures will be concentrated in different segments of the agricultural industry (growing and processing of agricultural products), food and light industries, recreation and tourism.

Thus, even remaining within the group of Russian economic outsiders, the North Caucasian republics will strengthen their economic development. Consequently, dependence of republican budgets will be reduced (from a third to a quarter relative to the current level).

The region will still to be characterized by a high level of official unemployment registered with all existing methods, although this level will remain a formal index. The situation in the group of the most problem republics (Chechnya, Ingushetia, and Dagestan) is expected unchangeable; the level of "shadow" employment there (including small-scale production sphere) will be the highest.

\section{Income Level and Life Standards}

The first decade of the XXI century was associated with a stable and very dynamic income growth of wide sections of the population in this region. In future, the pace of this process will depend on the general state of the Russian economy and budget. However, it is reasonable to believe that the general trend for the rise in living standards will be retained. Since the federal center considers income growth and expanding of middle class population to be one of the main ways to reduce the level of local radicalism and general conflict of republican societies, the latter are most likely to continue increasing their material welfare.

In terms of official income level, the republics can hardly achieve the average Russian level by 2030. However, de facto they will be on this level, as the material resources of the local population, in addition to employment, will still be significantly supplemented by shadow wages. Nevertheless, for the general social prospect, a more important factor appears the growing prosperity able to expand and modernize consumer standards, and ultimately living practices, behavioral stereotypes of most population of the North Caucasus.

\section{Sociocultural Contemporarization}

Despite many conservative trends in present-day life of the North Caucasus, their combination is not able to put paid to the contemporaryization of the region (Berezhnoy, 2002; "Islam in North Caucasian republics", 2002; Kisriev 2004; 
Babich, 2005; Babich, 2007; Markedonov, 2010). And not just because it is a part of Russia - a secular state with a strong innovative culture, having its own "bridgeheads" in the region. Not all processes, which determine a contemporary sociocultural dynamics of the republics, can be treated as "traditionally protective". Moreover, there is a complex "bunch" of contradictory trends, combining the whole spectrum of development vectors varying from "traditional" to "contemporary" within one social and geographical space. Additionally, each republic and national community, as well as their individual territory and professional segments have a specific variable correlation between tradition and innovation.

Giving a brief overview of the possible realities of the region in 2025-2030, one should be aware that this period is the time of adult life beginning for people born in the first decade of the century, whose personal formation occurred under sociopolitical and socioeconomic stabilization of the region and the country. This generation will be more pragmatic and focused on a successful professional career and higher education, the value of which is now recognized by the majority of the population. Two recent censuses have recorded a rapid growth of high school youth and people with higher education. With all possible critical reservations, the younger generation (like the whole population of the North Caucasus) will have a wider social and cultural horizon by 2030.

However, the educational level of the population, as a rule, is inversely correlated with the level of its religiosity (or at least with the rate of religious fanaticism). It is reasonable to believe that the percentage of "zealous" Moslemin (regardless of their belonging to Islam or Wahhabism) in the region will decrease. It is a very positive trend for the eastern republics of the North Caucasus, taking into account the correlation between the religious zeal of the population, sizes of radicalistic communities and general extremist activity.

However, even by 2030 the upgraded groups will be a minority in nearly all national communities of the region. Traditionalistic population with a dominant of conservative attitudes and values is expected to have a high percentage in the national capitals, to say nothing about the provinces. The situation varying significantly from republic to republic, the main bridgeheads of sociocultural traditionalism, like at present, will be concentrated in the east of the North Caucasus.

\section{Regional Terrorist Underground}

The centers of terror are likely to remain in a number of republics for more than one decade. Not only in 2015 or 2020, but also in 2030 (and probably later) fire and explosions will still happen in this region. But there are reasons to believe that at this time the scale of regional underground and general terrorist activity will be significantly lower than in 20082013 (Sushchiy, 2010; "Violence in the North Caucasus," 2009).

From four present-day terrorist centers, only Dagestan is sure to keep its position. By 2030, the Chechen and Ingush undergrounds will transform into sporadic activities of certain small groups of militants. In 15-20 years, Kabardian armed underground has little chance for preserving its structure (Sushchiy, 2012).

There are several main reasons contributing to the decrease in terrorist activity in the region. In addition to the efficient operation of security forces, there is a general reduction in the number of republican youth, connected with the gradual demographic modernization of the nations; next, it is sociocultural modernization reducing the potential support group and replenishment of the armed underground. Finally, one should consider the evolution of the regional underground, its transformation into a segment of an integrated criminal and corrupt-terrorist complex, formed in the North Caucasus over the last 10-15 years.

Over the past few years, there was a complete (and repeated) rotation in the administration of the underground. As far as this continuous change of the leaders occurs, the amount of really "ideological" ones is reduced; although the number of them using "jihad" as an ideological covering for rather profitable criminal activity is gradually increasing. Such inner transformation does not remain unnoticed by republican societies, cuts down both moral authority and the level of mass social support of "forest brotherhood". Further development by this trajectory dooms the North Caucasian armed underground to an increasingly deep social marginalization, which over time may turn it into one of the segments of the republican criminal world.

Thus, the area of the increased terrorist activity in the North Caucasus can be gradually reduced to the territorial borders of Dagestan, where by this time a significant (the most significant) part of regional terrorist acts (like Chechnya in early XXI) will be localized. However, Dagestan terrorist underground is surely exposed to gradual reduction. At least by 2030, the number of people joining "Forest brothers" as well the scale of republican IAF can be significantly cut down

\section{Conclusions}

The outlined prospect of the North Caucasus appears quite optimistic. Maintaining a conservatively bureaucratic version of Russia's evolution (no real alternative is observed), such progressive development scenario of the region is the most 
realistic for 10-20 years' prospect. Moreover, slow, extensive features of the modernization model are more comfortable for the republican society, rather than "storm and stress" of the 1990s. Political and socioeconomic stability of the Russian Federation is the essential condition for accumulation of social positive, small portions of which collected for decades can substantially change the image of the North Caucasus.

There is another significant factor. No matter how successful the future development of the region is, the settlement and integrated optimization of life of many national societies with developed self-consciousness (i.e., a certain distance from the internal Russian ethnic and sociocultural core of the Russian Federation) will always be a topical problem in the North Caucasus.

This article was prepared in frame of project part of the state task in the field of scientific activities of the Ministry of Education and Science of the Russian Federation, research № 30.1577.2014/K.

\section{References}

Babich, I. (2005). The North Caucasus: the Statehood by the national, Islamic and political movements. Central Asia and the Caucasus, 6.

Babich, I. (2007). Islamic Movements in contemporary North Caucasus. Qloballasma prosessinde Qafqaz ve merkezi Asiya, 3, 10831092.

Berezhnoy, S. E., et al. (2002). Islam in modern republics of the North Caucasus. Rostov-on-Don: SKNC VSH.

Degoev, V., \& Ibragimov, R. (2006). The North Caucasus: post-Soviet results as a guide for action. M.

Denisova, G. S., \& Ulanov, V. P. (2003). Russians in the North Caucasus: analysis of transformation of sociocultural status. Rostov-onDon: SKNC VSH.

Dobaev, I. P. (2009). Contemporary terrorism: regional dimension. Rostov-on-Don: SKNC VSH. Ethnoethatism and ethnocracy in Southern Russia. (2006). Rostov-on-Don.

Gammer, \& Moshe, (2005). Between Mecca and Moscow. Islam, politics, and political Islam in Chechnya and Dagestan. Middle Eastern Studies, 41(6), 833-848.

Investment Atlas of Southern Russia. (2009). Rostov-on-Don.

Islam in North Caucasian republics. (2002). Rostov-on-Don: SKNC VSH.

Khoperskaya, L. L., \& Kharchenko, V. A. (2005). Local interethnic conflicts in Southern Russia 2000-2005. Rostov-on-Don: SSC RAS.

King, C. (2008). The ghost of freedom: a history of the Caucasus. New York: Oxford University Press.

Kisriev, E. F. (2004). Islam and state power in Dagestan. M.: OGI.

Lipina, S. A. (2010). Strategic priorities of socioeconomic development of the North Caucasian republics. Ways and methods of their achievement. M.: Lenand.

Markedonov, S. (2005). Of ethnic and religious factor in the political processes in the Caucasus region. M: MAX-press.

Markedonov, S. (2010). Radical Islam in the North Caucasus. Evolving threats, challenges, and prospects. Washington, DC: CSIS.

Matishov, G. G., (2011). The North Caucasus: problems and prospects for development. Atlas of sociopolitical problems, threats, and risks of Southern Russia, 5.

Matishov, G. G., Batiev, L. V., \& Pashchenko, I. V. (2009). Reasons and conditions for tension increase, search for the ways of stabilization in the North Caucasus.

Atlas of sociopolitical problems, threats, and risks in Southern Russia, 4.North Caucasus in the national strategy of Russia. (2008). Moscow: Rosinformagrotech.

Sushchiy, S. Ya. (2010). Terrorist underground in the west of North Caucasus (Chechnya, Dagestan, Ingushetia). Rostov-on-Don: SSC RAS.

Sushchiy, S. Ya. (2012). The North Caucasus: realities, problems, and prospects of the first third of XXI century. M.:, Lenand.

Tishkov, V. (1997). Ethnicity, nationalism and conflict in and after the Soviet Union. The mind aflame. London: SAGE Publications.

Tishkov, V. (2004). Chechnya: Life in a war-torn society. California Series in Public Anthropology, 6, 302.

Tkhagapsoev, Kh. G. (2007) Ethnoetatism in sociopolitical reality of contemporary Russia. Ethnoetatism and ethnocracies in Southern Russia, 9-23.

Violence in the North Caucasus-2009: A bloody year. Human Rights and Security Initiative. Retrieved April 12, 2014, from www. csis. org/ hrs/

Xenophobia in Southern Russia. (2004). Rostov-on-Don: SKNC VSH. 